\title{
Article
}

\section{Rheology Control of Isododecane with Newly Synthesized Organogelators; 3,3',4,4'-Benzophenone Tetracarboxamide}

\author{
Yuichi SAKANISHI ${ }^{*}$, Yusuke NARUSAKA ${ }^{* *}$, Mami ITOH $^{* *}$, and Takashi SAEKI ${ }^{* * \dagger}$ \\ ${ }^{*} R \& D$ Center, Organic Chemical Products Company, DAICEL Corporation, \\ Ohtake, Hiroshima 739-0695, Japan \\ ${ }^{* *}$ Graduate School of Science and Engineering, Yamaguchi University, \\ Ube, Yamaguchi 755-8611, Japan \\ (Received : October 9, 2013)
}

\begin{abstract}
Rheology control additives for hydrophobic fluids, so-called organogelators, are frequently utilized within a wide range of industrial and commercial applications. Numerous organogelators are available; however, their uses are normally limited to highly specialized applications. In this study, we synthesized organogelators having different chemical side chains of C6 to C18 derived from 3,3',4,4'-benzophenone tetracarboxylic acid, and evaluated their rheological control effects for several oils. The molecular mechanisms for thickening and/or gelation properties were probed using transmission electron microscopy (TEM), molecular orbital calculation, differential scanning calorimetry (DSC) analysis and infrared absorption spectrum (IR) analysis. We found that some of our synthesized compounds can significantly increase the viscosity of isododecane, and do so by assembling in worm-like structures due to hydrogen bonding among amide groups. An organogelator into which both a 2-ethylhexayl group and oleyl group were introduced also synthesized not only a thickening property but also a significant viscoelastic property for isododecane, a solvent for which none of the commercial organogelators tested was adequate.
\end{abstract}

Key Words: Organogelator / Benzophenone / Amide / Isododecane

\section{INTRODUCTION}

Rheology control for hydrophobic fluids is frequently needed in a wide range of industrial and commercial applications, such as inks, paints, food, cosmetics, pharmaceutical products, petroleum products, and so on. Recently, the field of hydrophobic-supramolecular polymeric materials including self-assembly technology has grown rapidly over the past decade. ${ }^{1-10)}$ One of the methods to obtain a self-assembly structure is to use low-molecular-weight compounds as hydrophobic solvents. A number of such chemical reagents, which can transform low-viscosity organic liquids into gels and/or gel-like substances, have been synthesized as organogelators. ${ }^{11,12)}$ For suitable molecular design of organogelators, both self-assembly of molecules into nanofibers via hydrogen bonding and formation of a threedimensional network structure due to van der Waals interaction might be important. Low-molecular-weight organogelators constructed from many aromatic rings have been reported; e.g.,

To whom correspondence should be addresses

E-mail: saeki@yamaguchi-u.ac.jp with biphenyl structure ${ }^{13)}$, bisurea compounds ${ }^{14)}$, and so on. Skeleton structures of benzene or cyclohexane with chemical side chains have also been reported as organogelators. Within these compounds, benzene-1,3,5-tricarboxamide is well known as an effective organogelator for various oils, the thickening property of which may be related to the hydrogen bonds of amide groups. ${ }^{15)}$ Shikata, et al. ${ }^{16)}$ investigated both the supramolecular structure and dynamics of benzene-1,3,5tricarboxamide in hydrophobic fluid. The hydrogen bonds of three amide group quickly formed a coordinate structure like a polymer molecule, which entangled and showed remarkable viscoelastic property. However, unlike the case in a polymer, relaxation of the entanglement occurred by the rearrangement of two supramolecular structures, following the Phantom Crossing Model. The effects of introducing chirality chains ${ }^{17,18)}$ and polymer chains ${ }^{19)}$ have previously been reported. Webb, et $a l^{20)}$ and Tong, et $a l .{ }^{21)}$ examined N,N',N",N"' -1,2,4,5tetra alkyl pyromellitamide. This organogelator showed a similar thickening effect as that of tricarboxamide, in which four amide groups of chemical side chains were expected to increase the intermolecular force. In these above-mentioned studies, the target oils were general organic solvents like 
decane or hexane; however, little information is available regarding versatility for common oils. It is known that the versatilities of commercially available organogelators are not so high and their uses are normally limited for their individual applications.

In this study, the gelation ability and versatility of commercial available organogelators for several kinds of oils were examined. Organogelators having benzophenone as a skeleton and four various alkyl amides were synthesized and evaluated. Furthermore, organogelators having two different alkyl chains were synthesized for different crystallinity and solubility effects. We evaluated our synthesized compounds for several kinds of oils, and in detail for isododecane, which is a basic raw material for cosmetics. The objective of this study was to develop effective organogelators with consideration of both their chemical structures and their rheological properties.

\section{EXPERIMENTAL PROCEDURE}

\subsection{Materials}

Organogelators currently on the market were selected for the preliminary experiment; the main contents, brand names, and suppliers are listed in Table I with numbering. Additives $\mathbf{1 , 4 , 5}$ are widely used in cosmetics and pharmaceutical products, while additive $\mathbf{3}$ is frequently used in food products. Additives $\mathbf{2 , 6 , 7}$ are used to control the fluidity of paints and inks.

The basic chemical structure of the newly synthesized organogelators, 3,3',4,4'-benzophenone tetracarboxylic dianhydride (BTDA-R), is shown in Fig. 1. The chemical side chains, $\mathrm{R}$ and $\mathrm{R}$ ', were varied as shown in Table II. Compounds 1-7 were synthesized from benzophenone tetracarboxylic acid tetrachloride with an alkylamine and recrystallized. In the case of compounds 8-11, benzophenone

Table I. Commercially available additives.

\begin{tabular}{|c|c|c|c|}
\hline $\begin{array}{l}\text { Additive } \\
\text { No. }\end{array}$ & Material & Brand name & Company \\
\hline 1 & Stearoyl inulin & Leoparl LIS2 & $\begin{array}{c}\text { Chiba Flour Milling } \\
\text { Co., Ltd. }\end{array}$ \\
\hline 2 & $\begin{array}{l}\text { Hydrogenated } \\
\text { castor oil }\end{array}$ & $\begin{array}{l}\text { SN } \\
\text { thickener }\end{array}$ & $\begin{array}{l}\text { SAN NOPCO } \\
\text { Co., Ltd. }\end{array}$ \\
\hline 3 & $\begin{array}{c}\text { Triglycerin } \\
\text { pentastearate }\end{array}$ & TAISET 50 & $\begin{array}{l}\text { Taiyo Kagaku } \\
\text { Co., Ltd. }\end{array}$ \\
\hline 4 & $\begin{array}{l}\text { N-2-ethylhexanoyl-L } \\
\text {-glutamic acid } \\
\text { di-n-butyl amide }\end{array}$ & EB-21 & $\begin{array}{l}\text { Ajinomoto } \\
\text { Co., Inc. }\end{array}$ \\
\hline 5 & $\begin{array}{c}\text { N-lauroyl-l-glutamic acid } \\
\text { di-n-butyl amide }\end{array}$ & GP-1 & $\begin{array}{l}\text { Ajinomoto } \\
\text { Co., Inc. }\end{array}$ \\
\hline 6 & Aromatic polyurea & BYK-410 & BYK Co., Ltd. \\
\hline 7 & Aromatic polyurea & BYK-E410 & BYK Co., Ltd. \\
\hline
\end{tabular}

tetracarboxylic dianhydride was reacted with an alkylamine $\left(\mathrm{RNH}_{2}\right)$. The thus-obtained amic acid was compensated with an alkylamine $\left(\mathrm{R}^{\prime} \mathrm{NH}_{2}\right)$ with the addition of diisopropyl carbodiimide as a catalyst and recrystallized. Compounds 1-7 had four side chains of the same group (homo-compound), while compounds 8-11 had two pairs of different groups (hetero-compounds). Compounds 8-11 might include a small amount of regioisomers as shown in Fig. 2.

The hydrophobic fluids (solvents) examined in this study were liquid paraffin (MORESCO Co., Kobe, Japan), isododecane (Maruzen Petrochemical Co., Tokyo), cetyl octanoate (99.5+\%, Kokyu Alcohol Industries, Co., Chiba, Japan), and sunflower oil (Nikko Chemicals, Co., Tokyo). All the solvents were used without further purification. The commercial additives were dissolved at $80-120{ }^{\circ} \mathrm{C}$ with the concentration of $1.0 \mathrm{wt} \%$, while synthesized compounds were dissolved at $100{ }^{\circ} \mathrm{C}$ for 10 hours.

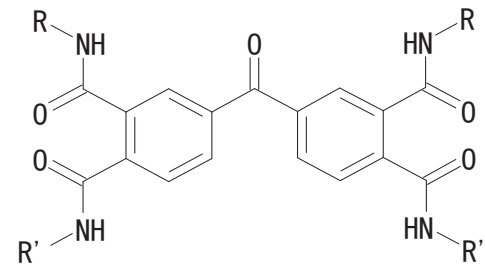

Fig. 1. Chemical structure of BTDA-R (1- 10).

Table II. Chemical side chains of BTDA-R (1- 11).

\begin{tabular}{ccc}
\hline $\begin{array}{c}\text { Compound } \\
\text { No. }\end{array}$ & $\mathrm{R}$ & $\mathrm{R}$ \\
\hline $\mathbf{1}$ & $\mathrm{n}-\mathrm{C}_{6} \mathrm{H}_{13}$ & $\mathrm{n}-\mathrm{C}_{6} \mathrm{H}_{13}$ \\
2 & $\mathrm{n}^{-} \mathrm{C}_{8} \mathrm{H}_{17}$ & $\mathrm{n}-\mathrm{C}_{8} \mathrm{H}_{17}$ \\
3 & 2 -ethylhexyl & 2-ethylhexyl \\
4 & $\mathrm{n}-\mathrm{C}_{12} \mathrm{H}_{25}$ & $\mathrm{n}-\mathrm{C}_{12} \mathrm{H}_{25}$ \\
5 & $\mathrm{n}-\mathrm{C}_{14} \mathrm{H}_{29}$ & $\mathrm{n}-\mathrm{C}_{14} \mathrm{H}_{29}$ \\
6 & $\mathrm{n}-\mathrm{C}_{18} \mathrm{H}_{37}$ & $\mathrm{n}-\mathrm{C}_{18} \mathrm{H}_{37}$ \\
7 & Oleyl & Oleyl \\
8 & 2 -ethylhexyl & Oleyl \\
9 & $\mathrm{n}-\mathrm{C}_{18} \mathrm{H}_{37}$ & $\mathrm{Oleyl}$ \\
10 & 2 -ethylhexyl & $\mathrm{n}-\mathrm{C}_{18} \mathrm{H}_{37}$ \\
11 & 2 -ethylhexyl & $\mathrm{n}-\mathrm{C}_{12} \mathrm{H}_{25}$ \\
\hline
\end{tabular}
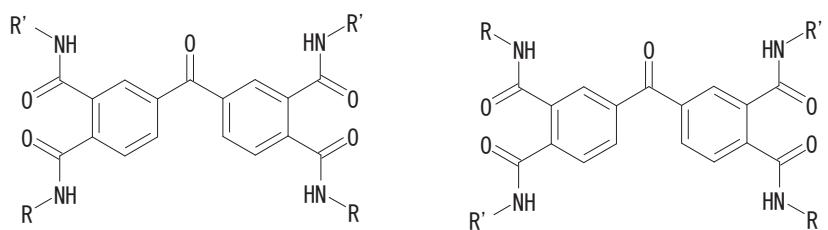

Fig. 2. Regioisomers of compounds $8-11$. 


\subsection{Measurements}

The rheological properties were measured using a cone and plate rheometer (NRM-2000R, Elquest Co., Chiba, Japan) at $25{ }^{\circ} \mathrm{C}$. The diameter and angle of the cone were $17.1 \mathrm{~mm}$ and $3^{\circ}$, respectively. The equilibrium flow property was measured for the shear rate range from 2 to $500 \mathrm{~s}^{-1}$. The frequency dependence of the viscoelasticity of the sample was measured at a strain of 0.1 with a frequency of sine wave oscillation from 0.63 to $37.6 \mathrm{rad} / \mathrm{s}$. The self-assembled structure of compound $\mathbf{2}$ was observed by a transmission electron microscopy (TEM, JEM-140, JEOL Co., Tokyo). The organogelator was dissolved in hexane, and the sample was attached to a support film grid and dried for 2 hours. Then, the sample was stained by osmium tetraoxide $2 \%$ aqueous solution for 4 hours. The accelerating voltage of the TEM was $100 \mathrm{kV}$. The infrared absorption (IR) spectrum of the organogelator crystal was measured using Fourier transfer IR equipment (FT/IR-6200typeA, Shimadzu Co., Kyoto, Japan). The measurements were conducted both by the $\mathrm{KBr}$ pressedpellet method and the Nujol mull method using $\mathrm{CHCl}_{3}$ as a solution. Calorific values and crystallization temperatures of $10 \mathrm{wt} \%$ organogelator solutions in $\mathrm{CHCl}_{3}$ were measured by differential scanning calorimetry (Hitachi High-Tech Science Co., Tokyo). The initial temperature, the final temperature, and the heating rate were $-60{ }^{\circ} \mathrm{C}, 80^{\circ} \mathrm{C}$, and $5{ }^{\circ} \mathrm{C} / \mathrm{min}$, respectively.

\section{RESULTS AND DISCUSSION}

The effects of commercially available additives $\mathbf{1}$ and $\mathbf{2}$ on the viscosity of liquid paraffin are displayed as equilibrium flow curves in Fig. 3. Liquid paraffin, which had a viscosity of $140.0 \mathrm{mPa} \cdot \mathrm{s}$ at $25^{\circ} \mathrm{C}$, showed Newtonian properties. The flow curves with the two additives show typical shear thinning properties. The viscosities increased around 4 times with the additives at a shear rate of $10 \mathrm{~s}^{-1}$.

The equilibrium flow properties of organic solvents with all the commercial additives were measured and the relative viscosities with respect to the original organic solvents at a shear rate of $10 \mathrm{~s}^{-1}$ are shown in Table III. If a sample had cloudy appearance and/or sedimentation even after extended agitation, we did not conduct any rheological measurements and judged the additive as ineffective for the particular organic solvent. In such a case, we used a hatched cell in the table to indicate poor solubility. Additives 1, 2, 3 and 5 showed several-times increases in viscosity, but only for their typical solvents, while additives 4,6 , and 7 were insoluble for all organic solvents. We could not find any effective additives for isododecane.

To search for a more universal additive, compounds 1-11 were synthesized as organogelators. The equilibrium flow properties of $1.0 \mathrm{wt} \%$ solutions were measured and the viscosities at a shear rate of $10 \mathrm{~s}^{-1}$ were converted into the relative viscosities as shown in Table IV. Again, we used hatched cells for samples with poor solubility. The homocompound with stearyl group chains (compound 6) was the most effective at increasing the relative viscosities for all the solvents. And, while the commercial additives were not effective for isododecane, several synthesized compounds could increase the viscosity of the solvent. Especially, homocompound $\mathbf{2}$ and hetero-compound $\mathbf{8}$ showed significant viscosity increases (relative viscosities of more than 600). Both 2-ethylhexyl homo-compound (compound 3) and oleyl homo-compound (compound 7) showed poor solubility for isododecane; however, the hetero-compound with both 2-ethylhexyl and oleyl (compound 8) dissolved well in the solvent and dramatically increased the viscosity of the

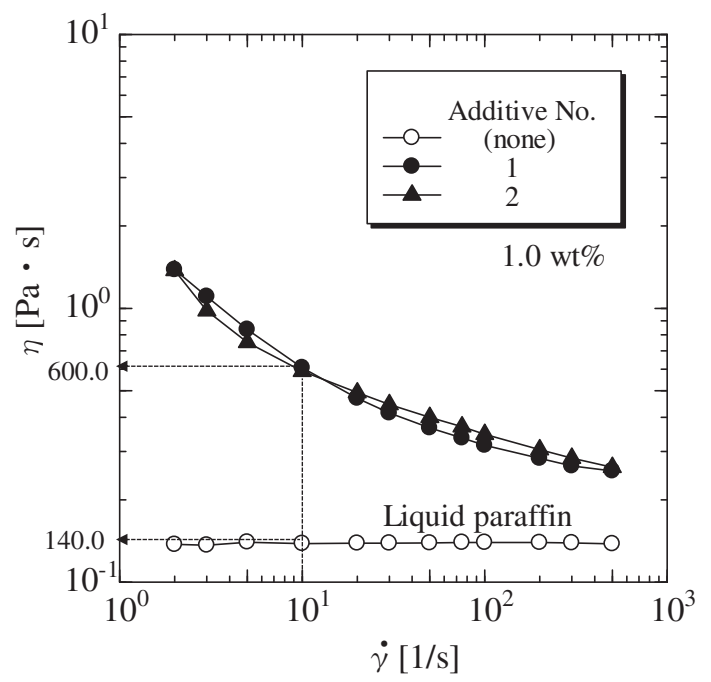

Fig. 3. Equilibrium flow curves for commercially available additives ;1 and 2 .

Table III. Viscosity of organic solvent with additives $1-7$ in at $25^{\circ} \mathrm{C}$.

\begin{tabular}{|c|c|c|c|c|}
\hline \multirow{2}{*}{ Organic solvent } & \multirow{2}{*}{$\begin{array}{c}\text { Viscosity } \\
\text { liquid paraffin }\end{array}$} & \multicolumn{2}{|c|}{ Relative viscosity of additives ( - ) } \\
\cline { 3 - 5 } & 138.5 & 4.382 & 2 & 3 \\
\hline isododecane & 1.2 & 1 & 250 \\
\hline sunflower oil & 54.9 & 11.8 &
\end{tabular}

The concentration of additives is $1.0 \mathrm{wt} \%$. 
solution. The different levels of the relative viscosity between solvents may be explained in terms of their polarity. Also, the thickening properties of the synthesized compounds might relate to internal structures built by compound molecules.

In order to consider a coordinate structure consisting of compound $\mathbf{2}$, the stabilization energy between two molecules of compound $\mathbf{2}$ was calculated. The evaluations for molecular structures and stabilization energy were performed by using the program of SCIGRESS Ver. 2.3 (Fujitsu Co., Tokyo) with PM5. Fig. 4 shows the obtained coordinate structure consisting of two molecules, in which hydrogen bond interaction, namely, the hydrogen atoms of an amide group, is coordinated to the oxygen atom of an amide group in another molecule. Such 'one lies on the top of another' structures stack repeatedly; consequently a worm-like structure would be formed with self-assembly.

The self-assembled structure built up with compound $\mathbf{2}$ in hexane was observed by transmission electron microscopy (TEM), as shown in Fig. 5. Compound 2 formed not only normal- range chains but also bundled structure in the solvent. The self-assembled structures were built by numerous intertwined fibers with lengths of 30-160 nm. An oil gel might be formed by the intertwining of such worm-like structure within the solvent.
Fig. 6 shows the FT-IR spectra of compound 2 with isododecane solution. Chloroform solution was also measured for comparison, which can dissolve compound $\mathbf{2}$ without changing the solution viscosity. The IR bands of $\mathrm{CHCl}_{3}$ solution were observed at $3294 \mathrm{~cm}^{-1}\left(v_{\mathrm{N}-\mathrm{H}}\right.$, amide A), $1650 \mathrm{~cm}^{-1}\left(v_{\mathrm{C}=\mathrm{O}}\right.$, amide $\left.\mathrm{I}\right)$, and $1520 \mathrm{~cm}^{-1}\left(\delta_{\mathrm{N}-\mathrm{H}}\right.$, amide II), attributable to characteristics of non- hydrogen bonded amide groups. On the contrary, the IR spectra in highly viscous isododecane solution showed distinct hydrogenbonding interaction between amide groups; IR bands were observed at $3241 \mathrm{~cm}^{-1}$ (amide A), $1631 \mathrm{~cm}^{-1}$ (amide I), and $1551 \mathrm{~cm}^{-1}$ (amide II). We confirmed that the self-assembly of compound $\mathbf{2}$ into nanofibers occurred through intermolecular hydrogen bonding interaction of amide groups.

The equilibrium flow properties of isododecane with the well-dissolved compounds are displayed in Fig. 7. Here, compounds $\mathbf{2}, \mathbf{4}, \mathbf{5}$, and $\mathbf{6}$ were homo-compounds, while 8-10 were hetero-compounds. All the solutions show around 1000 times increase of viscosity compared to additivefree isododecane at the shear rate of $10 \mathrm{~s}^{-1}$. In addition, the solutions behave as pseudoplastic fluids, as the viscosity decreased with an increase in shear rate; this behavior may relate to the entanglement structure formed by the compounds.

The viscoelasticities of isododecane solutions containing

Table IV. Viscosity of organic solvent with compounds 1-11 in Organic Solvents at $25^{\circ} \mathrm{C}$.

\begin{tabular}{|c|c|c|c|c|c|c|c|c|c|c|c|c|}
\hline \multirow{2}{*}{ Organic solvent } & \multirow{2}{*}{$\begin{array}{l}\text { Viscosity } \\
(\mathrm{mPa} \cdot \mathrm{s})\end{array}$} & \multicolumn{11}{|c|}{ Relative viscosity of compounds ( - ) } \\
\hline & & 1 & 2 & 3 & 4 & 5 & 6 & 7 & 8 & 9 & 10 & 11 \\
\hline liquid paraffin & 138.5 & & & & & & 13.1 & 2.9 & & 4.9 & 3.2 & \\
\hline isodocecane & 1.2 & & 629.9 & & 330.4 & 299.0 & 258.2 & & 676.3 & 115.9 & & 449.8 \\
\hline sunflower oil & 54.9 & & & & & 1.6 & 2.3 & & 1.6 & & & \\
\hline cetyl octanoate & 11.8 & & & & & & 13.8 & & 11.2 & 30.3 & & \\
\hline
\end{tabular}
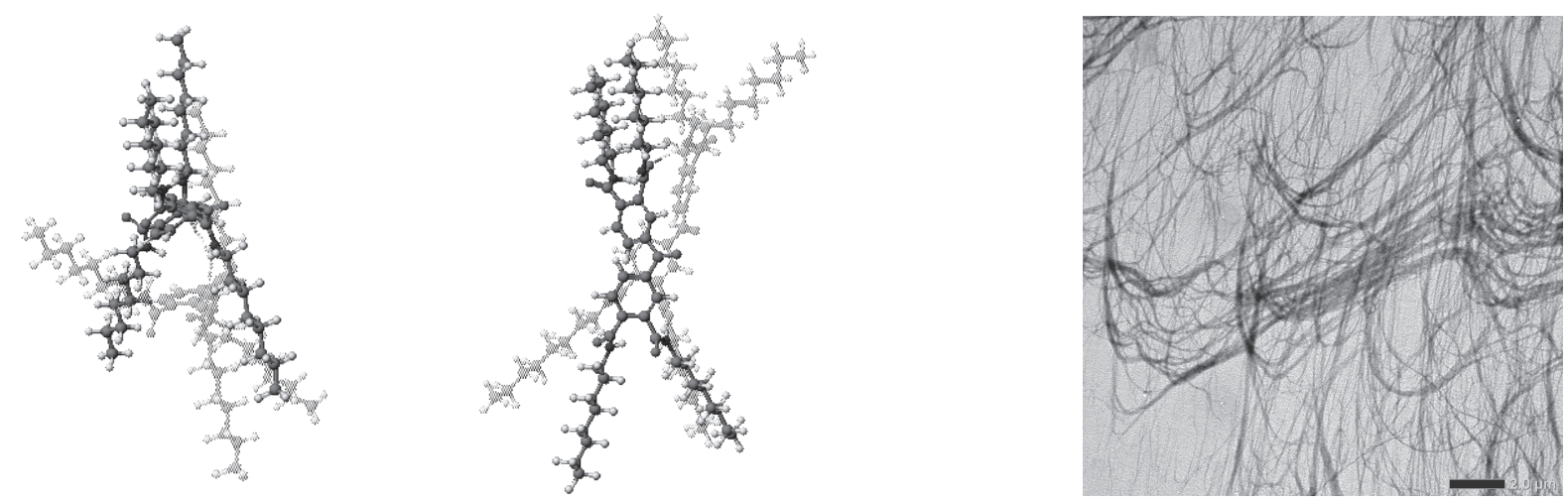

Fig. 4. Calculated coordinate structure consist of 2 .

Fig. 5. TEM image of gel network formed by compound 2 in hexane. 
0.5-2.0 wt $\%$ of compound $\mathbf{2}$ and $\mathbf{8}$ are shown in Figs. 8 and 9 , respectively. The loss elastic modulus $\left(G^{\prime \prime}\right)$ of the oil solution using compound 2 was larger than the storage elastic modulus $\left(G^{\prime}\right)$ over the measured shear rates regardless of the additive amount (Fig. 8). By contrast, in the case of compound 8 (Fig. 9), the $G^{\prime}$ of 0.5 wt $\%$ solution was larger than the $G^{\prime \prime}$ at a higher shear rate range. The cross point of $G^{\prime}$ and $G^{\prime \prime}$ lines moved to the lower shear rate range with the increase of compound concentration. Finally, the $G^{\prime}$ and $G^{\prime \prime}$ were independent of the frequency and the solution becomes gelatinous. Such a viscoelastic property might be caused by a self-assembled structure built by compound $\mathbf{8}$ molecules.

Hanabusa et al. ${ }^{13)}$ explained the molecular design of organogelators in terms of their solubility in solvents, selforganization, and the control of crystalline properties. Table V shows the crystallization temperatures and the calorific values of compound 1-11 measured with DSC. Compound 1 and 2 showed no clear crystallization temperature in $\mathrm{CHCl}_{3}$. As the length of the linear alkyl chains in compounds 4 , $\mathbf{5}$, and $\mathbf{6}$ increased, the crystallization temperature became

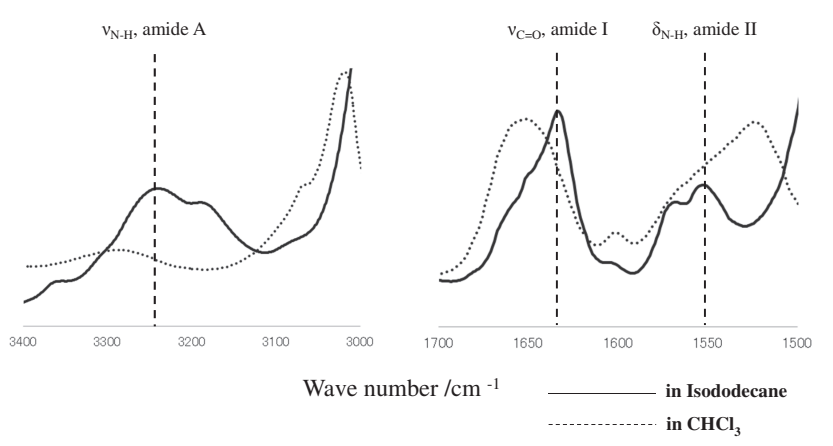

Fig. 6. FT-IR spectra of 2.

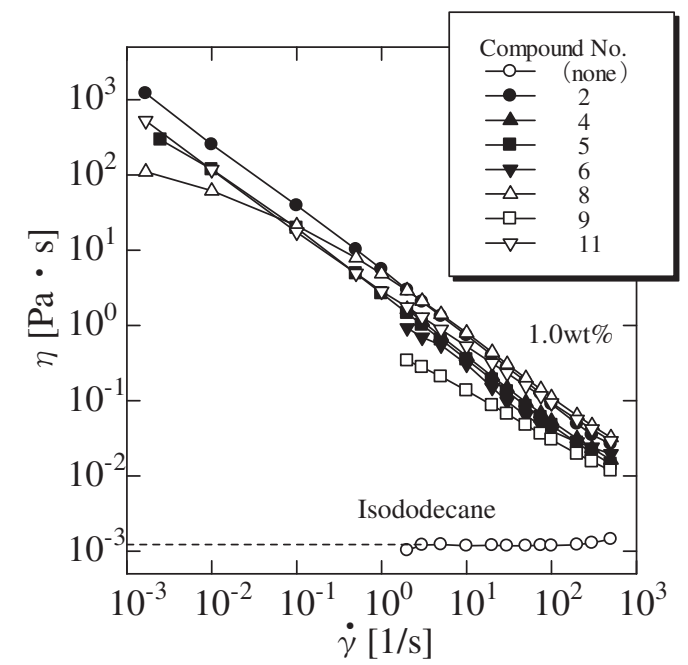

Fig. 7. Equilibrium flow curves for synthesized compounds. higher. This implies that the crystalline property is affected by the intermolecular forces of the side chains. Although compound $\mathbf{3}$ has the same carbon number as compound $\mathbf{2}$, the compound had a much higher crystallization temperature due to the lower molecular mobility caused by the bulky

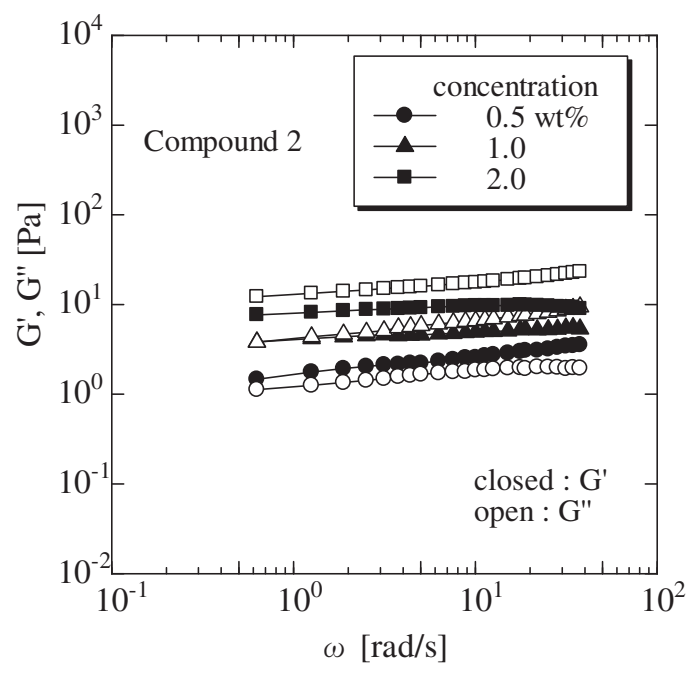

Fig. 8. Viscoelastic properties of compound 2 at different concentrations.

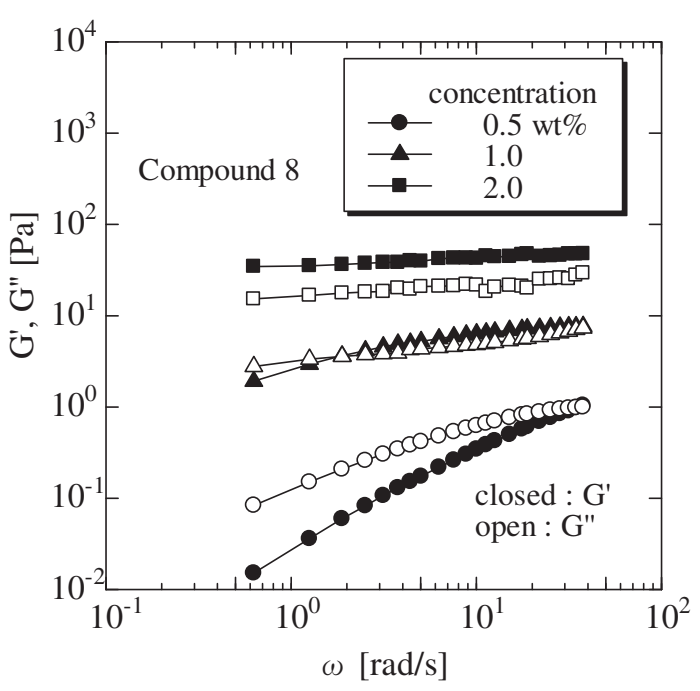

Fig. 9. Viscoelastic properties of compound 8 at different concentrations.

Table V. The crystallization temperatures of 3-6 in $\mathrm{CHCl}_{3}$ and calorific values at that temperature.

\begin{tabular}{ccc}
\hline $\begin{array}{c}\text { Compound } \\
\text { No. }\end{array}$ & $\begin{array}{c}\text { Calorific value } \\
(\mathrm{kJ} / \mathrm{mol})\end{array}$ & $\begin{array}{c}\text { Crystallization } \\
\text { temperature }\left({ }^{\circ} \mathrm{C}\right)\end{array}$ \\
\hline 3 & 85.9 & 72.0 \\
4 & 59.2 & -30.8 \\
5 & 55.7 & -10.7 \\
6 & 127.5 & 11.34 \\
\hline
\end{tabular}


2-ethylhexyl group. In spite of having a larger carbon number, compound 7, having an unsaturated group, did not crystallize which might relate to the higher solvent affinity of the alkenyl group. Compound 8-11, having two types of side chains, did not have a clear crystallization temperature between $-60{ }^{\circ} \mathrm{C}$ and $80{ }^{\circ} \mathrm{C}$. Solubility seems to be a key property for the synthesized organogelators.

\section{CONCLUSION}

3,3',4,4'-benzophenone tetracarboxamide were newly synthesized in this study as organogelators for hydrophobic fluids. Seven commercially available additives and 11 synthesized compounds were examined using a cone and plate rheometer. From the results, the ability for the rheological control of hydrophobic fluids might be related to self-assembled structures of the compounds' molecules. Hetero-compounds synthesized in this study showed typical viscoelastic properties. We suggested that controlling the crystallinity and solubility in hydrophobic fluids are the key elements for synthesizing appropriate organogelators.

\section{REFERENCES}

1) Ciferri A, Supramolecular Polymers, ed by Marcel Dekker Inc, New York (2005)

2) Lehn J-M, Polym Int, 51, 825-839 (2002).

3) Bosman AW, Brunsveld L, Folmer BJB, Sijbesma RP, Meijer EW, Macromol Symp, 201, 143-154 (2003).
4) Brunsveld L, Folmer BJB, Meijer EW, Sijbesma RP, Chem Rev, 101, 4071-4097 (2001).

5) Ciferri A, Macromol Rapid Commun, 23, 511-529 (2002).

6) Velten U, Rehahn M, Chem Commun, 23, 2639-2640 (1996).

7) Hofmeier H, Hoogenboom R, Wouters MEL, Schubert US, J Am Chem Soc, 127, 2913-2921 (2005).

8) Hilger C, Stadler R, Macromolecules, 23, 2095-2097 (1990).

9) de Greef TFA, Smulders MMJ, Wolffs M, Schenning APHJ, Sijbesma RP, Meijer EW, Chem Rev, 109, 5687-5754 (2009).

10) Terech P, Weiss RG, Chem Rev, 97, 3133 (1997).

11) Brunsveld L, Folmer BJB, Meijer EW, Sijbesma RP, Chem Rev, 101, 4071 (2001).

12) Bouteiller L, Adv Polym Sci, 207, 79-112 (2007).

13) Jang W-D, Aida T, Macromolecules, 37, 7325 (2004).

14) Hanabusa K, Suzuki M, SEN'I GAKKAISHI, 65, 5 (2009).

15) Hanabusa K, Koto C, Kimura M, Shirai H, Kakehi A, Chem Let, 26, 429 (1997).

16) Shikata $T$, Nishida $T$, Hanabusa $K$, Nihon Reoroji Gakkaishi, 40, 41-47 (2012).

17) Stals PJM, Smulders MMJ, Martín-Rapín R, Palmans ARA, Meijer EW, Chem Eur J, 15, 2071-2080 (2009).

18) Tristan M, Smulders MMJ, Palmans ARA, Meijer EW, Macromolecules, 43, 1981-1991 (2010).

19) Roosma J, Mes T, Lecle`re, P, Palmans ARA, Meijer EW, J Am Chem Soc, 130, 1120-1121 (2008)

20) Webb JEA, Crossley MJ, Turner P, Thordarson P, J Am Chem Soc, 129, 7155-7162 (2007).

21) Tong KWK, Dehn Sabrina, Webb JEA, Nakamura Kio, Braet F, Thordarson P, Langmuir, 25, 8586-8592 (2009). 